ger Sonneneinstrahlung - und damit verminderter Umwandlung von 7-Dehydro-Cholesterol zu Cholecalciferol scheinen mehr Anaphylaxie-gefährdete Patienten zu wohnen als in den sonnenreichen Staaten im Südwesten.

Fazit: Im Jahr 2004 wurden in den USA knapp 2,5 Mio. Adrenalin-Autoinjektoren rezeptiert. Dies entspricht einer Verordnungsrate von 5,7 pro 1.000 Einwohner. Es bestehen allerdings deutliche regionale Unterschiede mit etwa doppelt sovielen Verordnungen im Nordosten der USA und einer Halbierung im Südwesten. Dies könnte auf einer Assoziation von Sonneneinstrahlung und Anaphylaxierisiko beruhen - je mehr Sonne, desto weniger Anaphylaxien.

Camargo CA et al. Regional differences in EpiPen prescriptions in the United States: the potential role of vitamin D. J Allergy Clin Immunol 2007; 120: 131-6

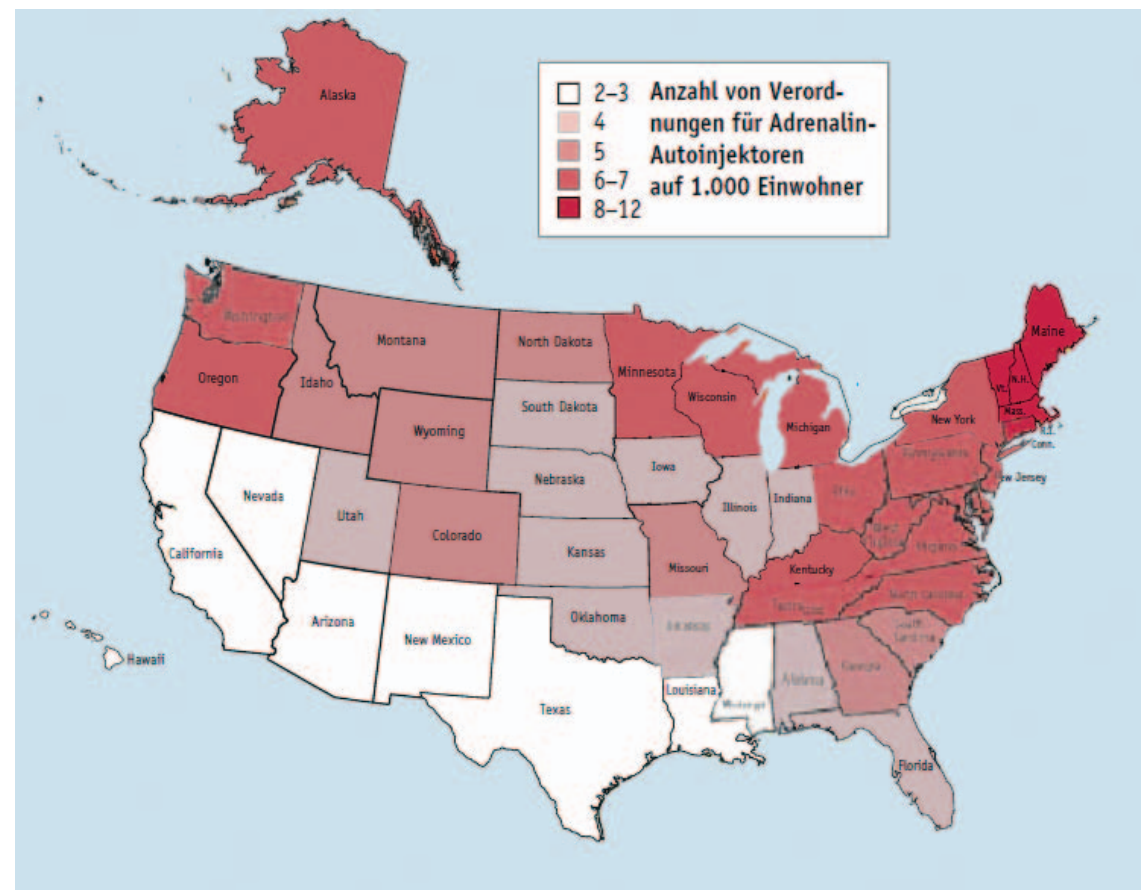

Landkarte der Vereinigten Staaten - im Süden sind Anaphylaxien offensichtlich seltener.

\section{Aufgepasst mit Säureblockern bei Nahrungsmittelallergie!}

\section{Allergene sind Proteine, und die werden normalerweise durch das saure, pepsinhaltige Milieu im Magen so angegriffen, dass ihre Allergenität stark abnimmt. Doch was ist, wenn der Magen nicht mehr so sauer ist?}

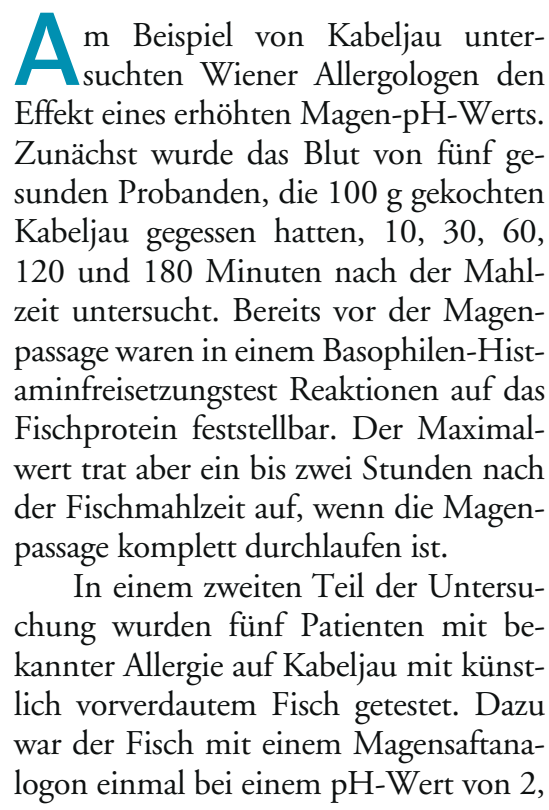

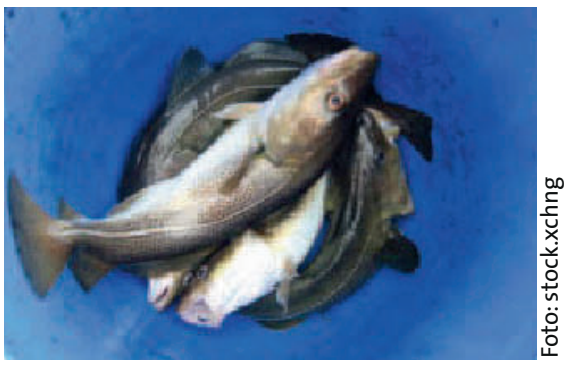

Das Magenmilieu bestimmt die Allergenität von Fisch mit.

das entspricht dem normalen $\mathrm{pH}-$ Wert des Magens, und einmal bei einem $\mathrm{pH}$ Wert von 3 versetzt worden. Der bei pH 2 vorbehandelte Fisch ergab eine deutlich geringere allergische Reaktivität als der bei pH 3 vorverdaute, und zwar sowohl im Histaminfreisetzungstest als auch im Pricktest. Das bei pH 3 behan- delte Fischprotein entsprach dabei in der Allergenität etwa demjenigen von unverdautem Fisch.

In doppelblinden plazebokontrollierten Provokationstests zeigte sich, dass bei Konsum von Fisch, der bei $\mathrm{pH} 3$ vorverdaut worden war, die minimale Dosis zur Auslösung einer allergischen Reaktion gegenüber dem bei $\mathrm{pH} 2$ vorverdauten Protein um das 10- bis 30-fache verringert war. Sie lag je nach Proband bei 1,11 bis $3,11 \mathrm{mg}$ Protein. Bisher berechnete Dosen von $6 \mathrm{mg}$ als Grenzwert für die Allergieauslösung müssen also zumindest bei beeinträchtigter Magenverdauung in Frage gestellt werden.

Fazit: Ist der Magen-pH-Wert erhöht, werden Fischproteine deutlich weniger abgebaut. Damit sinkt die zur Auslösung der allergischen Reaktion notwendige Allergenmenge. Nahrungsmittelallergiker sollten daher bei der Einnahme von Medikamenten zur Erhöhung des Magen-pH-Werts vorsichtig sein. $\quad f k$

Untersmayr E et al. Incomplete digestion of codfish represents a risk factor for anaphylaxis in patients with allergy. J Allergy Clin Immunol 2007; 119: 711-7 